\title{
Investigation of a Behavioural Response Model for Fire Emergency Situations in Secondary Schools
}

\author{
MAHMUT HORASAN \\ Lecturer, Department of Civil and Building Engineering \\ DOROTHY BRUCK \\ Senior Lecturer, Department of Psychology \\ Victoria University of Technology \\ P.O. Box 14428, MMC Melbourne, VIC 3000 \\ Australia \\ email: administrator@civbldstaff@gnu.vut.edu.au
}

\begin{abstract}
Though a large number of studies have been carried out in emergency movement and egress only few have considered evacuation of schools. A model to investigate and simulate the probable behavioural responses during fire related emergency situations has been developed for primary (elementary) and secondary (junior and senior high) schools. As part of this broader research program, a more limited study has been undertaken. The aim of this study is to determine the likelihood of responses by secondary school students to fire alarms and cues. A questionnaire was used and the behaviours were considered in terms of how they changed as a function of a number of variables such as different fire cues and social environment, grade level, gender, previous fire and drill experience. Responses to the questionnaire were analysed to determine the most likely and unlikely behaviours from the model. The results indicate that for adolescents social environment can be the most pertinent variable influencing the decision to initiate risk reducing behaviour. Therefore fire safety training for this age group must include presentation of psychological and social factors (such as the concepts of "pluralistic ignorance" and "diffusion of responsibility") that could influence an individual's behaviour during an emergency.
\end{abstract}

KEYWORDS: $\quad$ evacuation, egress, behavioural response modeling, fires at schools, fire-safety training 


\section{INTRODUCTION}

Evacuation of buildings in an emergency-related situation is a vital component of occupant safety. Some major research studies have been carried out in this area looking at various aspects of emergency evacuation such as behavioural response, human behaviour in emergency related situations, movement of people, and egress design. There is information available on the emergency evacuation of buildings including office buildings, residential apartments, public buildings, hospitals and sports complexes. However, among the large number of studies carried out in emergency movement and egress few have concentrated on or looked at evacuation of schools. Bryan [1], while investigating different aspects of egress design concepts, commented on school fire drills without going into much detail. In his chapter in the Fire Safety Handbook, Sharry [2] briefly looks at general design considerations of educational occupancies and emphasises the fact that younger children require safeguards not necessary for more mature occupants. Van Bogaert [3] discussed the physical, mathematical, psychological and practical aspects of school evacuations, however, he did not attempt to model them. Beck [4] emphasised the need to develop a model which would estimate occupant behavioural factors. This also was one of the recommendations in the Fire Safety and Engineering project conducted at the Warren Centre for Advanced Engineering by Beck and others [5].

It is known that emergency drills are often carried out regularly in schools. While aiming to train the staff and the students to achieve safe and quick evacuation in case of an emergency situation, these trial evacuations do not emphasise the behavioural (or psychological) status of school occupants under fire conditions and operate on general assumptions based on data obtained for premises occupied mainly by adult populations. Paulsen [6] traces the developments in the research into human behaviour in fire situations, however none of the studies he investigated considers age as a variable.

The Centre for Environmental Safety and Risk Engineering at Victoria University of Technology is conducting a multi-disciplinary research program to evaluate fire safety systems in buildings and to develop cost-effective building designs. The study described in this paper is part of a research project which aims to develop a model for primary and secondary schools ${ }^{1}$ in order to investigate and simulate probable behaviour during fire-related emergency situations and to incorporate it in a risk analysis model. A model which has been developed to initiate the investigations is explained in this study and it forms the basis of the survey conducted. The aim of this study was to determine the likelihood of secondary school students responding to fire alarms and cues in certain ways as proposed by the model.

\section{OVERVIEW OF THE MODEL}

Swartz [7] stated "the behaviour in fires consist of a far richer behaviour process than much conventional wisdom would suggest". This becomes obvious in attempts to model behaviour in fire related emergencies.

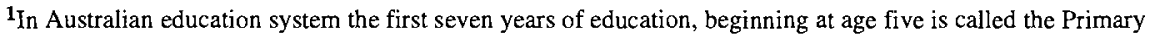
School (including the preparatory year), and the years 7 to 12 are called the Secondary school.
} 
A variety of models have been developed by a number of scientists over the years and they offer different approaches. The general human behaviour models previously developed by Bryan [1] and Canter, Breaux \& Sime [8] have been used as a starting point towards the construction of the behavioural model for students in a school environment.

A graphical representation of the model is given in Figure 1. The model covers three possible situations in a school/classroom environment: student alone, student in a room with peers without a teacher, student with or without peers in a room with a teacher.

With the assumption that the student(s) would follow a teacher's instructions during an emergency, the model concentrates more on the first two situations. The third situation needs to be treated as a separate model.

The students facing an emergency situation have to make decisions and take actions in order to solve the problem to reach safety [9]. The classification of actions (response patterns) which occur in building fire emergencies developed by Bryan [1] and similar ones by Bickman [10] and Canter [11] has been used as the guide in identifying behaviours which can be expected from students.

In the model all possible actions are laid out and the logical inter-action links are established. The format is suitable for further development as a deterministic and/or probabilistic simulation model.

The behaviour types are considered in two major categories:

i. Delay causing behaviour (options 1-6 in Figure 1), (Canter [11], describes them as "ineffective actions", )

ii. Responsive behaviour (options 7- 15 in Figure 1), (Canter [11], describes them as "effective actions", )

While the responsive behaviour would also have a time delay factor attached to them, it is the delay causing behaviour which would cause longer durations of time to be consumed prior to evacuation and thereby increase the risk to life.

There are two possible inputs to all behaviours which would affect the hierarchies of action: the arrival or interference of a teacher (or an adult) and reception of more cues. The arrival of a teacher will lead to the action titled "Follow Instruction" and will terminate the action sequence.

The model assumes arrival of further cues either primary (eg. smoke, flames, etc.) or secondary (sirens, people alerting others, etc.) will either trigger another action (more likely a responsive behaviour) or shorten the egress time.

\section{STUDENT RESPONSE STUDY}

A questionnaire was used and the likely behaviour of secondary school students were considered in terms of how they changed as a function of a number of variables. Of particular interest was the nature of behaviour when exposed to different fire cues, and whether behaviour was influenced by the social environment. Other variables such as grade level, gender, previous fire and drill experience were also considered. 
FIGURE 1. Behavioural response model of students in a fire emergency

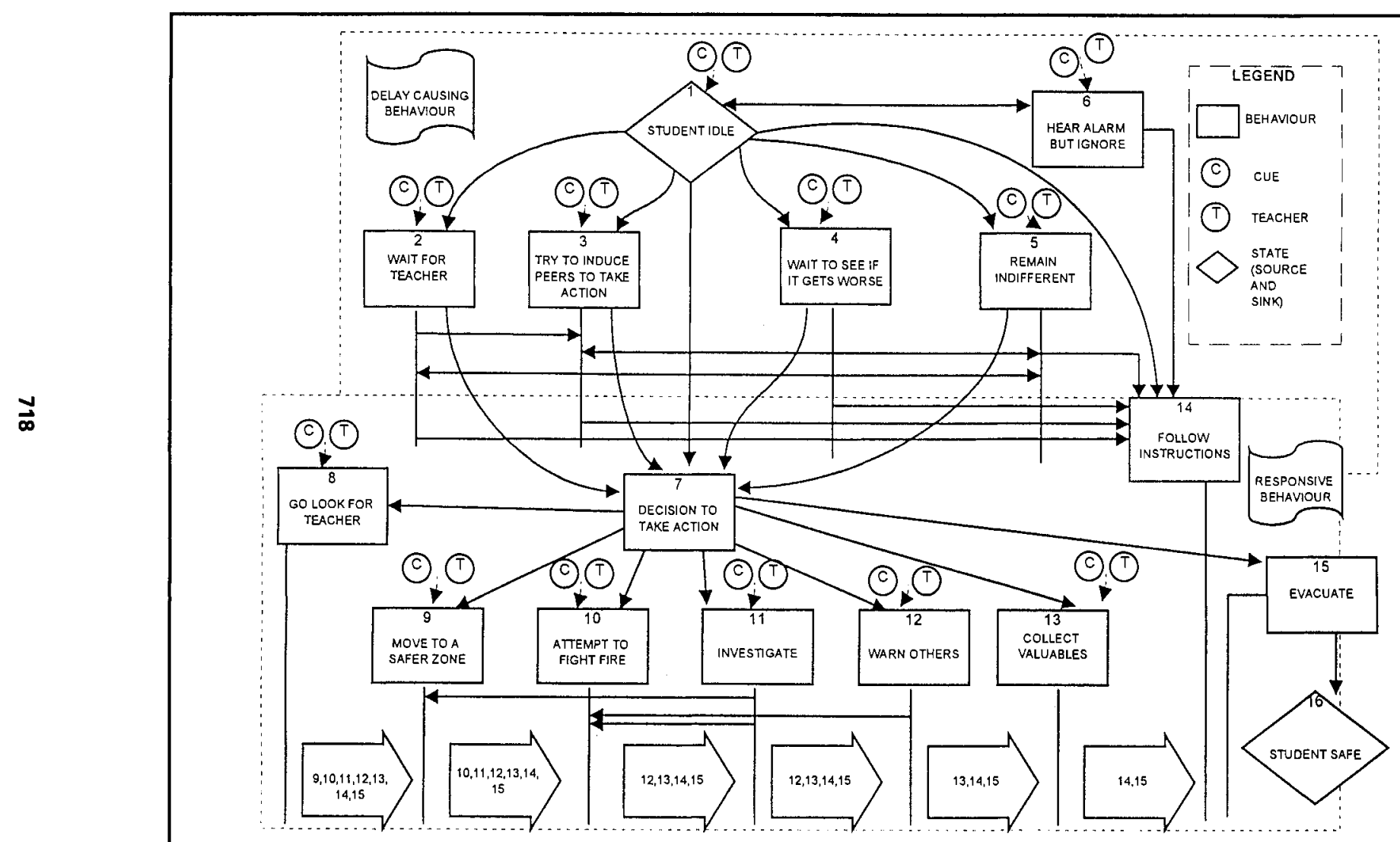




\section{METHOD}

\section{Subjects}

The questionnaires were completed by 170 students across grades 7 to 12 . The percentages in different year levels were, grades 7 and $8=34.7 \%$, grades 9 and $10=48.2 \%$, grades 11 and 12 $=17.1 \%$. The ages ranged from 12 to 20 years with a mean of $14.49(\mathrm{SD}=1.58)$. Fifty seven percent of the sample were males. Over half of the sample had been at the school for at least one year.

\section{The Questionnaire}

The questionnaire included all the relevant variables (gender, knowledge of escape routes, fire and smoke spread scenarios, previous experience of fire, and training) as illustrated by Wood [12] and related to motivation to evacuate. It comprised three sections. The first section contained questions on student's age, gender and familiarity with the school environment. The second section presented the student with six scenarios and aimed to collect information on most probable actions under given conditions

The scenarios manipulated three different variables: level and type of fire cues, the levels of ambiguity of cues similar to those defined by Levin [13], and the social environment. In the first three scenarios the student is alone while in the last three scenarios the student is in a class of peers who suggest no action. For each of these scenarios there were seven to nine behaviour options with a five point scale for responses changing from Very Unlikely to Very Likely. In general the behavioural responses were variations of the response options in the model (such as: spend 5 minutes trying to change their minds).

In the third section of the questionnaire a series of questions relating to the number of evacuation drills previously undertaken and the student's experiences of uncontrolled fire were asked. The question on extent of damage to property was asked separately from damage to human health/life. Once again students used a five point scale to make their ratings but in these questions the extremes were from 'None' to 'Major such as building destroyed' or 'Major such as Death'.

\section{Procedure:}

Two hundred questionnaires were given to the teachers at Footscray City Secondary College (Melbourne, Australia) with the request to administer as many as possible across all year levels in class group situations. One hundred and seventy two questionnaires were returned and two were eliminated as being unscorable.

\section{Data Analysis:}

Each subject had indicated their likelihood of doing a particular behaviour within each scenario and this was scored as follows: $-2=$ Very Unlikely, $-1=$ Unlikely, $0=$ Don't Know, $1=$ Likely and $2=$ Very Likely. Unless stated otherwise the following data analyses used these 
mean scores as the dependent variable and inferential statistics were conducted. The SAS [14] statistical package was used. The reader is referred to Pagano [15] for details of any of the statistical procedures mentioned in the results and the Annotations section at the end of the paper. Because of the large number of planned comparisons the cut-off levels for significance were adjusted using Bonferroni's adjustments [16].

\section{RESULTS}

Of initial interest was the issue of which behaviours the students were most likely to engage in. The following presents a hierarchy of behavioural responses ranked from 'most likely' to 'least likely' to occur across a range of scenarios. The number in brackets indicates the number of scenarios in which the item occurred. Only those behaviours which were presented in more than 2 scenarios are included.

- Leave the building immediately (6)

- Tell others (6)

- Find an extinguisher (4)

- Find a teacher (6)

- Collect important personal belongings (6)

- Wait for a teacher (4)

- Remain indifferent (6)

While the exact ranking varied somewhat from scenario to scenario these differences were not found to be significant (all p levels $>0.05$ ) using a series of Kruskal - Wallis tests [15].

Using the above groupings of behaviours Cronbach's Alphas [17] were computed and these correlations were above 0.7 . This indicates a high degree of reliability within these groupings on the questionnaire and the sample of responses represents a reliable sample of sufficient size to make meaningful generalisations (that is the sample was not found to differ significantly from population estimates).

\section{Likely Behaviours:}

From the mean values obtained for each response in each scenario, those mean values indicating "likely behaviours" were selected; that is, where the mean was between 0 (Don't Know) and 2 (Very Likely). Only two behaviours met this criteria in all six scenarios, these were "leaving the building immediately" and "telling everyone". These behavioural responses are graphed as a function of type of cues present and social environment in Figures 2 and 3.

A number of dependent $t$-tests were conducted to determine whether the presence or absence of peers significantly affected the level of likelihood of a particular behaviour. The level of significance was set conservatively at the 0.004 level. (Details of significant differences are included with the Figures 2 and 3). Significant differences were found for the alarm cue and fire cue situations when the student was alone compared to in a class with peers (who were suggesting no responsive action such as moving out of the room or evacuating the building) consistently decreasing the likelihood of the subject engaging in risk-reducing behaviour. 
FIGURE 2. Likelihood of a student leaving the building immediately

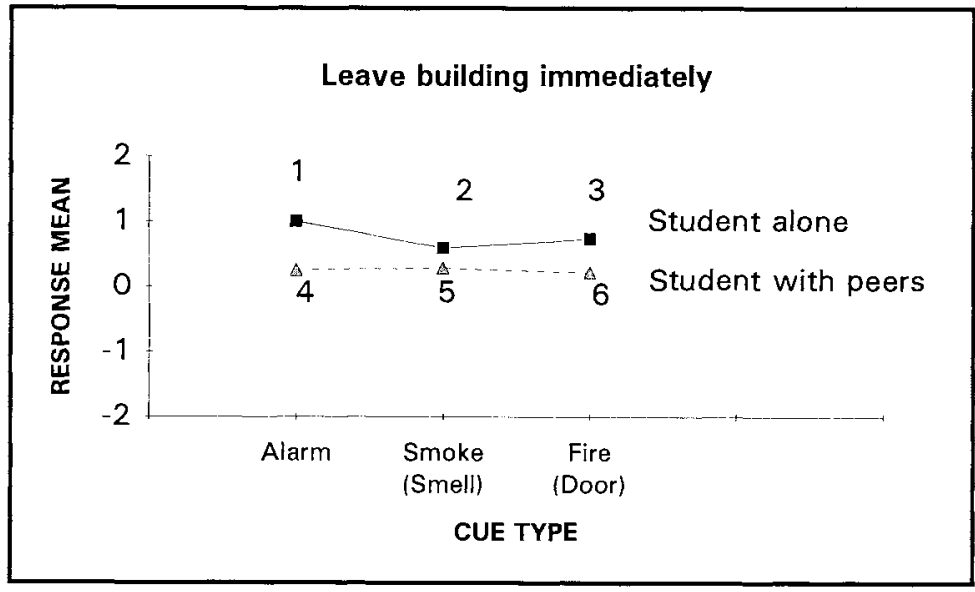

$$
\text { Alone versus Peers: } \quad 1 \& 4 * 2 \& 5 \mathrm{~ns} 3 \& 6 * \quad * \quad \begin{aligned}
& \text { KEY } \\
& \text { significant } \\
& \text { difference }
\end{aligned} \quad \mathrm{p}<0.004
$$

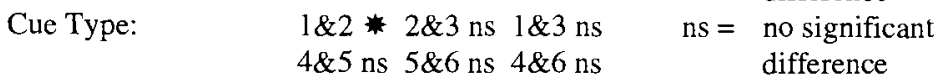

FIGURE 3. Likelihood of a student telling others about the fire

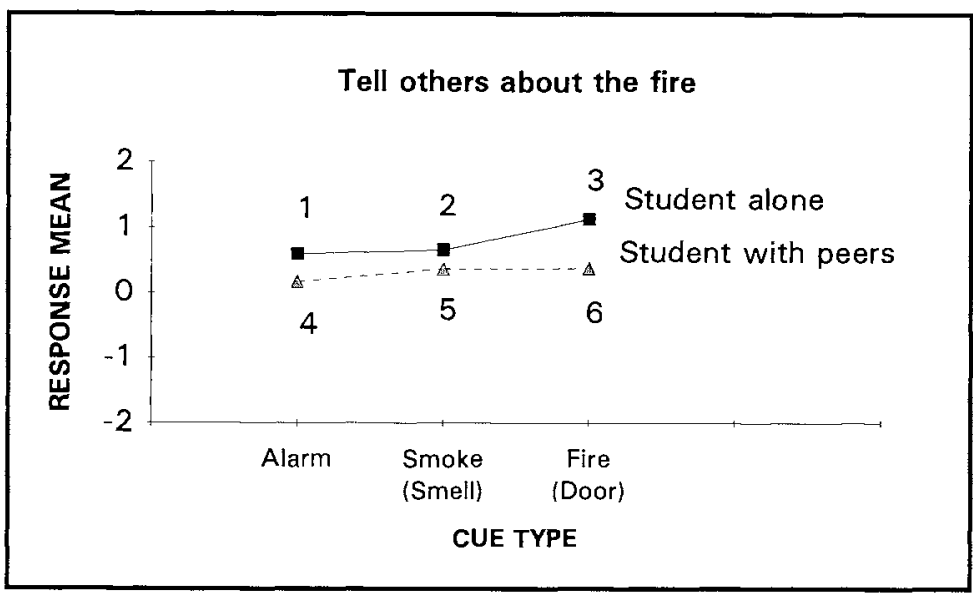
Alone versus Peers:
$1 \& 4 * 2 \& 5 \mathrm{~ns} 3 \& 6 *$
* = significant
$\mathrm{p}<0.004$
Cue Type:
$1 \& 2 \mathrm{~ns} \quad 2 \& 3 * 1 \& 3 *$ difference
$4 \& 5 \mathrm{~ns} \quad 5 \& 6 \mathrm{~ns} \quad 4 \& 6 \mathrm{~ns}$
$\mathrm{ns}=$ no significant
difference 
Further dependent $t$-test analyses were conducted to determine whether the type of fire cue in itself was also a significant determinant of these behaviours. It was found that, in general, cue type exerted little effect. The only two significant findings were, firstly, that a student hearing an alarm when alone was more likely to leave the building immediately than in any other situation (see point 1 on Figure 2), and, secondly, that a student, when alone in the presence of strong fire cues, was more likely to tell others about the fire than in any other situation (see point 3 on Figure 3). Of particular note from Figure 2 is that even in the presence of strong fire cues, if a student's peers suggest no action, then the mean 'likelihood' score for leaving the building immediately is only 0.21 . This score is closest to the 'Don't Know' response (0).

The only other behaviour that scored a mean positive value was "find an extinguisher", but only in the scenario where the student was alone and received strong fire cues. Even in this case the score was only marginally positive (0.06) suggesting a very high level of ambivalence.

\section{Very Unlikely Behaviours:}

Only three behaviours were found to have mean values consistently in the 'very unlikely' range, that is between -1 and -2 . From those asked in all six scenarios these were "wait for teacher" (overall mean $=-1.07$ ) and "remain indifferent" (overall mean $=-1.17$ ).

In the two scenarios involving the alarm only cue, the response "assume its a drill and ignore it" was also rated as 'very unlikely' (mean $=-1.23$ ).

\section{Student Variables:}

The data was then analysed to determine whether the behavioural responses varied as a function of certain characteristics of the students, these include grade level, gender, fire experience and drill experience. A level of 0.001 was set as the cut off for significance.

(a) Grade Level The six year levels were organised into three groups, junior, middle and senior. A trend was found for the senior group, when alone and hearing an alarm, to be more likely to "assume it's a drill and try to find out more" then junior or middle level students ( $\mathrm{F}=$ 6.51 , $\mathrm{df}=2,165, \mathrm{p}=0.002$, post-hoc Scheffe comparisons $\mathrm{p}<0.05$ ). However the mean response score fell between the "Don't Know" and "Unlikely" levels $(-0.3)$.

(b) Gender No significant differences were found between behavioural responses of males versus females. However $t$ tests indicated two noteworthy trends. When alone and with smoke cues, females were more likely to "leave the building immediately" (females mean $=0.89$, males mean $=0.36$ ). Males were more likely, with fire cues in a class situation to "find an extinguisher" (males mean $=-0.11$, females mean $=-0.4$ ).

(c) Fire Experience Responses relating to damage to property and human health/life were grouped into three categories: major $(n=11)$, medium $(n=8)$ and minor $(n=152)$. It was found that those students who reported direct experience of a fire that resulted in major damage to human life and health (defined as 'injury needing hospitalisation' or 'death') were significantly less likely to ignore smoke and fire cues, when alone, than less experienced peers, $(F=8.43$, $\mathrm{df}=2,56, \mathrm{p}=.0006$ ). 
In contrast, responses of those reporting fire experiences that resulted in property damage did not differ significantly from those with less experience.

(d) Drill experience The five point response scale was collapsed into two categories of previous drill experience, fewer than two or three or more No responses were significantly affected by level of previous drill experience.

\section{DISCUSSION}

The analyses of the questionnaire data from the secondary school students have a number of implications for the hypothesised model, for predicting students' behaviour in fire situations and for fire-safety training in schools.

The three options "wait for teacher", "remain indifferent" and "assume it's a drill and ignore it" could perhaps be eliminated when modeling secondary students as they seem to be unlikely responses.

It is of concern that in the present study the mean ratings of responsive behaviours in the different scenarios were not rated higher than 'likely'. Most mean values for responsive behaviour were in the region around 'don't know'. Consequently many students are exhibiting a considerable degree of ambivalence, even in a situation they believe is dangerous. The least ambivalence was found when a student was alone and heard an alarm. It would seem that students feel sure of what to do in a situation with a secondary cue, but become more unsure of how to act with primary cues of fire.

Of perhaps the greatest interest is how the behaviours noted as being 'likely' varied in relation to the different fire cues and social environment. It is quite clear that students, faced with a class of peers suggesting no action, are significantly less likely to initiate risk-reducing behaviours such as "leave building immediately" and "tell everyone" than if they were alone in the classroom. In the class situation the type of fire cues do not play a significant role in determining behaviour. In contrast when a student is alone the type of fire cue does influence behaviour.

This finding is consistent with the findings of Latane and Darnley $[18,19,20]$. They developed a model to explain why people help in some situations and not in others. They proposed that the intervention process is most likely to falter at the stages of interpreting the situation as an emergency or at the stage of deciding whether one is responsible for intervention. Latane and Darnley coined the phrase "pluralistic ignorance" to describe the situation where, if an emergency is ambiguous, each bystander is likely to appear unconcerned. As people are dependent on other's reaction for guidance on how to act, if no one interprets a situation as an emergency, then no one takes any action. While Latane and Darnley found this phenomena in ambiguous situations, in this study similar response patterns are evident even in situations not described as ambiguous. That is, even when the student is presented with a scenario that includes the words "you think it is a dangerous situation, your classmates suggest no action". Perhaps the reason for the differences lie in the age of the populations studied. Adolescents may be even more likely to look to peers for guidance on how to interpret a situation and even less willing than adults to initiate action that may lead to embarrassment (such as from overreacting to cues). 
Latane and Darnley also identified a second process "diffusion of responsibility", whereby the more people present at a potential risk situation, the more each individual believes that any responsibility to act should be shared by all present. These two phenomena could account for the findings of this study, as shown in Figures 2 and 3, where in the class situation regardless of the level and type of cues received, students were ambivalent about responsive actions such as leaving the building or warning others.

Interestingly, a follow up study by Berman, Barnes, Klentz and McQuirk [21] found that people's responses could be modified by training about the above two phenomena. This has implications for fire safety education. Specifically fire safety training for students should include presentation of psychological and social concepts (such as "pluralistic ignorance" and "diffusion of responsibility"), and students should be encouraged to see their applicability to emergency situations that they may encounter.

The most noteworthy aspect of the analyses for grade differences is the lack of significant differences in behavioural responses. The only finding was a trend for seniors, when alone, to assume an alarm was a drill and investigate. It would be worthwhile to conduct a similar questionnaire with younger age groups to see if primary age children display the same homogeneity of responses as adolescents.

The responses provided some evidence that, when alone, females were more likely to leave the building immediately or warn others in the presence of smoke cues than males. Males on the other hand, were more likely to find an extinguisher in the class situation when smoke was noted than females. While these differences did not attain significance, the authors believe that these differential responses may be real gender-related phenomena and feel a further study focusing on gender differences in this population may be warranted. This belief is supported by the fact that these findings are both consistent with conclusions of Canter, Breaux and Sime, drawn from studying domestic fires where females were more likely to warn others and leave the building and males were more likely to attempt to fight the fire [8].

If the students had had direct experience of a fire that involved damage to human health/life they were significantly less likely to ignore fire cues, when alone. Previous fire experience where damage to property was observed does not appear to be a factor influencing behaviour. These results demonstrate the importance of separating questions that relate to property damage from questions on human injury as a result of fire. Past fire evacuation drill experience had no effect on the likelihood of any behaviours (responsive or delay-causing) in any of the situations. This further suggests that any fire education program needs to be more extensive and diverse than simple drills.

\section{CONCLUSION}

The statistical analyses suggest that the behaviours depicted in the model and the questionnaire have a high degree of reliability for a population of secondary students and are applicable across a range of different scenarios where cue type and social environment are manipulated. Thus the model provides a solid basis for simulation studies. The next step will be to establish behaviour sequences via traditional or possibly computer based surveys. 
It is already known that time lost prior to the decision to take action is critical, and people should be trained to take responsive action as promptly as possible. The existing fire education programs address this issue by teaching people about fire alarms and cues. For the secondary school age group (12 to 20) Liebman [22] presents extensive guidelines about fire safety education with a focus on a variety of responsive behaviours such as escape drills and burn safety. However the results of the present study suggest that perhaps the most critical variable that determines how students will respond to primary and secondary fire cues is the behaviour of peers. Therefore fire safety training for this age group must include presentation of psychological and social factors that could influence an individual's behaviour during an emergency.

\title{
ACKNOWLEDGMENTS
}

The authors wish to acknowledge the assistance of Ms Kaylene Evers with statistical analysis; the cooperation of the Victorian Ministry of Education and Footscray City Secondary College; and helpful comments of Professor Vaughan Beck, Director, Centre for Environmental Safety and Risk Engineering. Funding support provided by a Victoria University of Technology Research Grant is also gratefully acknowledged.

\author{
ANNOTATIONS \\ df \\ a value that arises directly from the number of subjects and the number of \\ groups compared (degrees of freedom) \\ $\mathrm{F}$ \\ a numeric value obtained from analysis of variance calculations \\ $\mathrm{p} \quad$ level of significance obtained where 0.01 indicates a \\ $1 \%$ probability that the results occurred by chance \\ number of subjects \\ n \\ a numeric value obtained from $\mathrm{t}$-test calculations
}

\section{REFERENCES}

1. Bryan J.L., "Behavioural Response to Fire and Smoke", SFPE Handbook of Fire Protection Engineering, First Edition, Section1/Chapter 16, pp. 1/269-1/285, NFPA, Quincy - Massachusetts, September 1988.

2. Sharry J., "Educational and Assembly Occupancies", Fire Protection Handbook, Fifteenth Edition, Section 6/ Chapter 6, pp. 6/48 - 6/52, NFPA, Quincy - Massachusetts, September 1981.

3. Van Bogaert A.F., "Evacuating Schools on Fire", Eire Safety Science - Proceedings of the First International Symposium, pp. 551-560, 1987.

4. Beck, V.R., "Fire Safety System Design Using Risk Assessment Models: Developments in Australia", Fire Safety Science, Proceedings of the Third International Symposium, pp. 45-49, 1991.

5. Warren Centre Fire Safety and Engineering Reports, Volumes 1\&2, University of Sydney, December 1989. 
6. Paulsen, R.L., "Human Behaviour and Fires: An Introduction", Fire Technology, Vol.20, No.2, pp 15-27, May, 1984.

7. Swartz, J., "Human Behaviour and Fire", Fire Protection Handbook, Fifteenth Edition, Section 1/Chapter 2, pp. 1/4 - 1/7, NFPA, Quincy - Massachusetts, September 1981.

8. Canter, D., Breaux, J. and Sime, J. "Domestic, Multiple Occupancy and Hospital Fires", Fires and Human Behaviour, ed D. Canter, pp 83-95, First Edition, Chicester, Wiley, London, 1980.

9. Proulx G. and Passini R., "A stress model of people facing a fire emergency situation", Journal of Environmental Psychology, 1993.

10. Bickman, L., Edelman, P. and McDaniel, M., "A model of Human Behaviour in a Fire Emergency", National Bureau of Standards, Report No. NBS-GCR-78-120, December 1977.

11. Canter D., "Studies of Human Behaviour in Fire: Emprical Results and Their Implications dor Education and Design", Building Research Establishment Report, Department of Environment, Herts, 1985.

12. Wood, P.G. "A Survey of Behaviours in Fires", Fires and Human Behaviour, ed D. Canter, pp 83-95, First Edition, Chicester, Wiley, London 1980.

13. Levin, B.M., "Design as a Function of Responses to Fire Cues", General Proceedings of Conference: Research and Design 85: Architectural Application of Design and Technology Research, held at Los Angeles, CA, March 1985, pp. 289 - 294, A.I.A.F., Washington, D.C. , 1985.

14. SAS, Software Package and User Manual, Institute Inc., Cary, NC, USA, 1991.

15. Pagano, R.R. Understanding Statistics in the Behavioural Sciences, NY: West, 1986.

16. Keppel, G.,Design and Analysis, pp 147, Second Edition, Englewood Cliffs, NJ, Prentice Hall, 1982.

17. Leary, M.R. Introduction to Behavioural Research Methods, Belmont, CA, Wadsworth, 1991.

18. Latane B. and Darnley J.M. "Group Inhibition of Bystander intervention in Emergencies", Journal of Personality and Social Psychology, Vol 10, No 3, pp 215-221, 1968.

19. Latane B. and Darnley J.M. "Bystander Apathy", American Scientist, 57, pp 224-268, 1969.

20. Latane B. and Darnley J.M. "The Unresponsive Bystander: Why Doesn't He Help?" New York, Appleton, Century, Crofts, 1970.

21. Berman A.L., Barnes P.J., Klentz B. and McQuirk B "Increasing Helping Rates Through Dissemination: Teaching Pays.", Personality and Social Psychology Bulletin, 4, pp 406$411,1978$.

22. Liberman, L. "The Need to Know", Fire Protection Handbook, Fifteenth Edition, Section 1, Chapter 15, pp 1.8 - 1.15, , NFPA, Quincy, MA, 1981. 